\title{
Concurso Público Internacional Centro Matucana. Museo de la Memoria
}

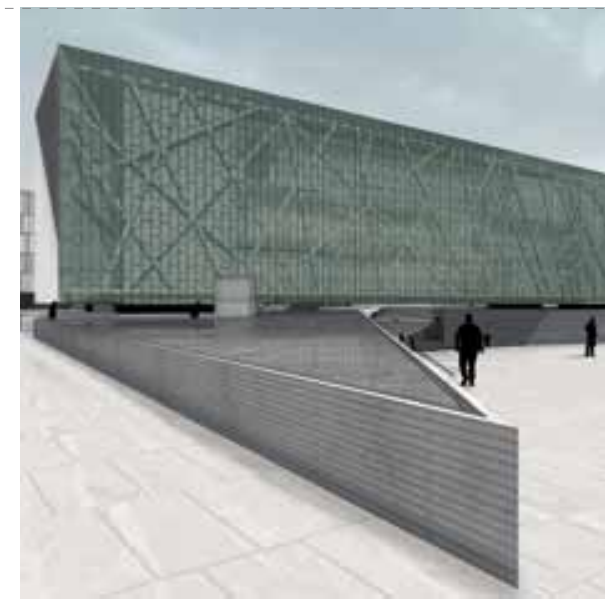

Ргіmer premio

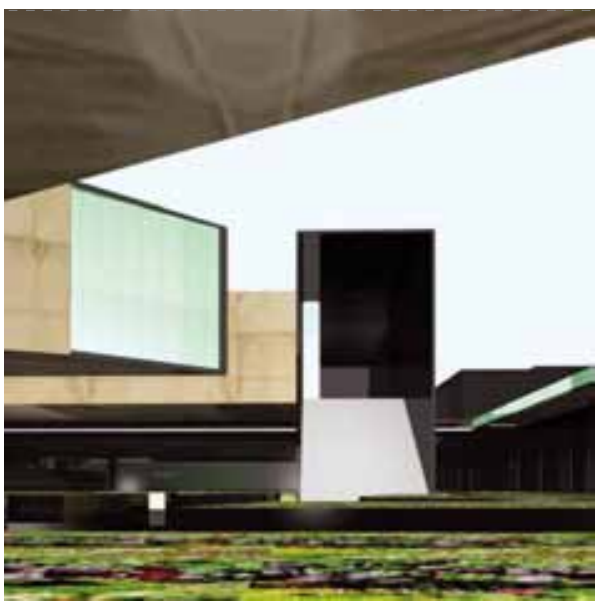

Segundo premio.

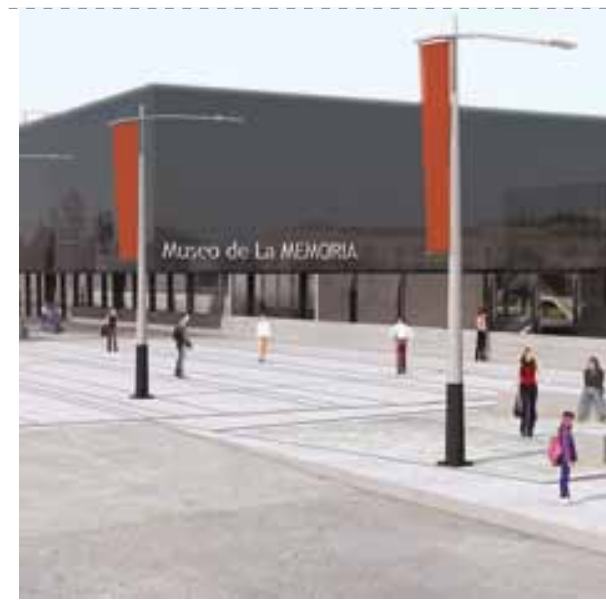

Tегсег ргеmio
El año 2007, el Ministerio de Obras Públicas (M.O.P), en el marco de intervención y ejecución de obras de cara al bicentenario de la República a celebrarse durante el 2010, instauró el concurso «Centro Matucana», espacio público que debía simbolizar el espíritu de celebración de los 200 años de vida independiente de nuestro país y que se ubicará en el cuadrante definido por las calles Matucana, Santo Domingo, Chacabuco y Catedral, en la zona de la Quinta Normal, Santiago, alcanzando una superficie de 15.727 $\mathrm{m}^{2}$. El llamado definía la intervención como la expresión arquitectónica de los valores de la identidad institucional de nuestra nación, constituyéndose en un espacio relevante para la vida pública, haciendo hincapié en el sentido de pertenencia que debía ofrecer el nuevo edificio al futuro público visitante. Además, dada la relevancia del espacio sugerido, se estima la conveniencia de que en tal superficie se inserte el Museo de la Memoria, que simbolizará la reflexión, aprendizaje y discusión de la temática de los Derechos Humanos a través de la historia de Chile.

De esta manera, el nuevo Museo de la Memoria, debía generar, a partir de su presencia, una experiencia informativa y educativa permanente y perdurable en el tiempo. Más allá de su condición de museo y la correspondiente presencia de infraestructura para exposiciones permanentes y temporales, el museo se siguiere como espacio Monumento-Memorial, lugar de vínculo con la historia de Chile, espacio para el debate y la conmemoración. Así, el edificio ofrecerá espacios para la conservación de documentos o material de registro; espacios de investigación que permitan el estudio, difusión y comunicación de los trabajos vinculados al rescate de la memoria nacional; áreas de documentación, catalogación de los documentos y colecciones presentes en el museo; exposición, espacios de muestra que acerquen al público los documentos de registro, poniendo en valor las colecciones existentes; zonas educativas, que permitan el traspaso de conocimiento y la instrucción a las presentes y futuras generaciones; esto acompañado de las respectivas áreas de dirección y administración que el recinto requiere.

A continuación revisaremos las imágenes y textos explicativos de los tres proyectos ganadores del Concurso Público Internacional, Centro Matucana. 
«La Construcción

de la Memoria»

\section{Primer Premio: Estudio América.}

Las memorias son figuras que viven en un mundo inconcluso, son fragmentos de hechos irrepetibles que no podrán suceder dos veces. Entendemos como memoria no un deseo juvenil de volver atrás, de sustituir lo insustituible. Para nosotros la memoria no es un arrepentimiento, es mirar el futuro sabiendo del pasado. Un museo de la memoria debería ser pensado a partir del carácter no lineal del tiempo y de sus imágenes, así como también del cómo podríamos almacenar y transmitir este conocimiento de manera amplia e imparcial. El orden territorial del centro de Santiago, íntimamente vinculado a la ciudad histórica, entiende el espacio público como no construido, configurado por la ocupación perimetral de la manzana. Entendemos esta historia y su tradición, pero consideramos la posibilidad de avanzar en la construcción de un nuevo territorio que tenga un claro compromiso con la diversidad ciudadana y los espacio democráticos.

El Centro Matucana será una manzana abierta. Se entiende y armoniza con la ciudad heredada, la incorpora y la transforma. El Museo de la Memoria no será un monumento aislado, suelto y sin responsabilidad urbana. Los elementos urbanos que componen el Centro Matucana tienen carácter cívico. La gran Plaza Inclinada, la Plaza de la Memoria y el patio jardín constituyen una secuencia espacial que ofrece una jerarquía urbana necesaria para un complejo metropolitano. Las Oficinas Públicas y Privadas se organizan alrededor de un Patio. La masa construida recompone la configuración urbana tradicional y permite a través de una planta baja ligera una permeabilidad necesaria y deseada. Un conjunto de edificios absorbe las oficinas [públicas y privadas], los usos comerciales y servicios, se organizan en torno a un jardín franqueado a la plaza, que contiene comercio, bares y restaurantes, delicias de la naturaleza humana a la espera de los encuentros.

El Museo se organiza en forma conceptual en dos momentos: La Barra y la Base. La primera, elevada, la historia, las informaciones y el vivir de la memoria abierta en las dos extremidades como quien deja la vida pasar. En la otra, la Base, primero la más profunda, minería, la producción, los estudios, la invención, los seminarios, los conocimientos de la tierra y del territorio y, en otro momento, el necesario apoyo de los sectores administrativos. La Barra, como espacio Museográfico específico,
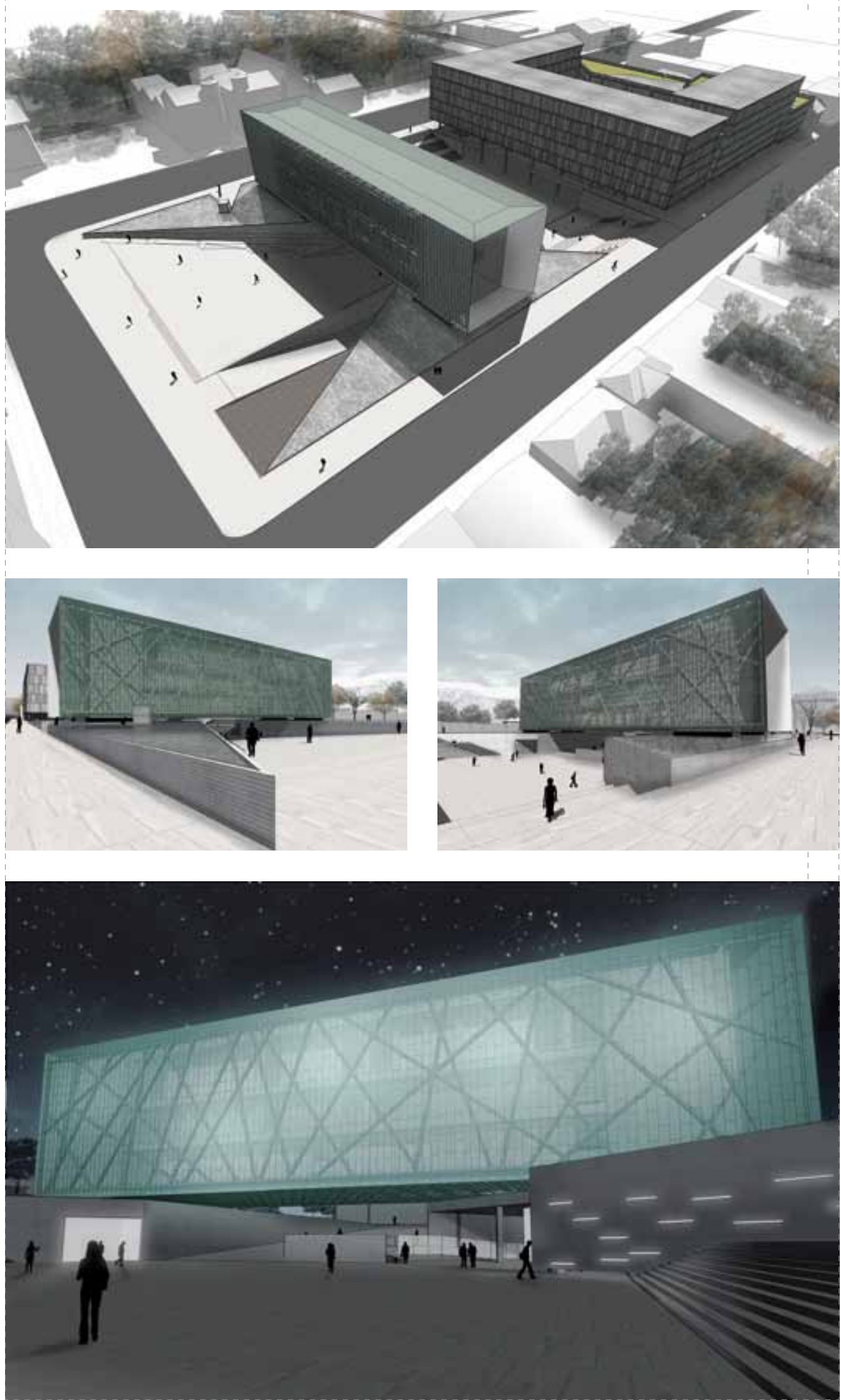


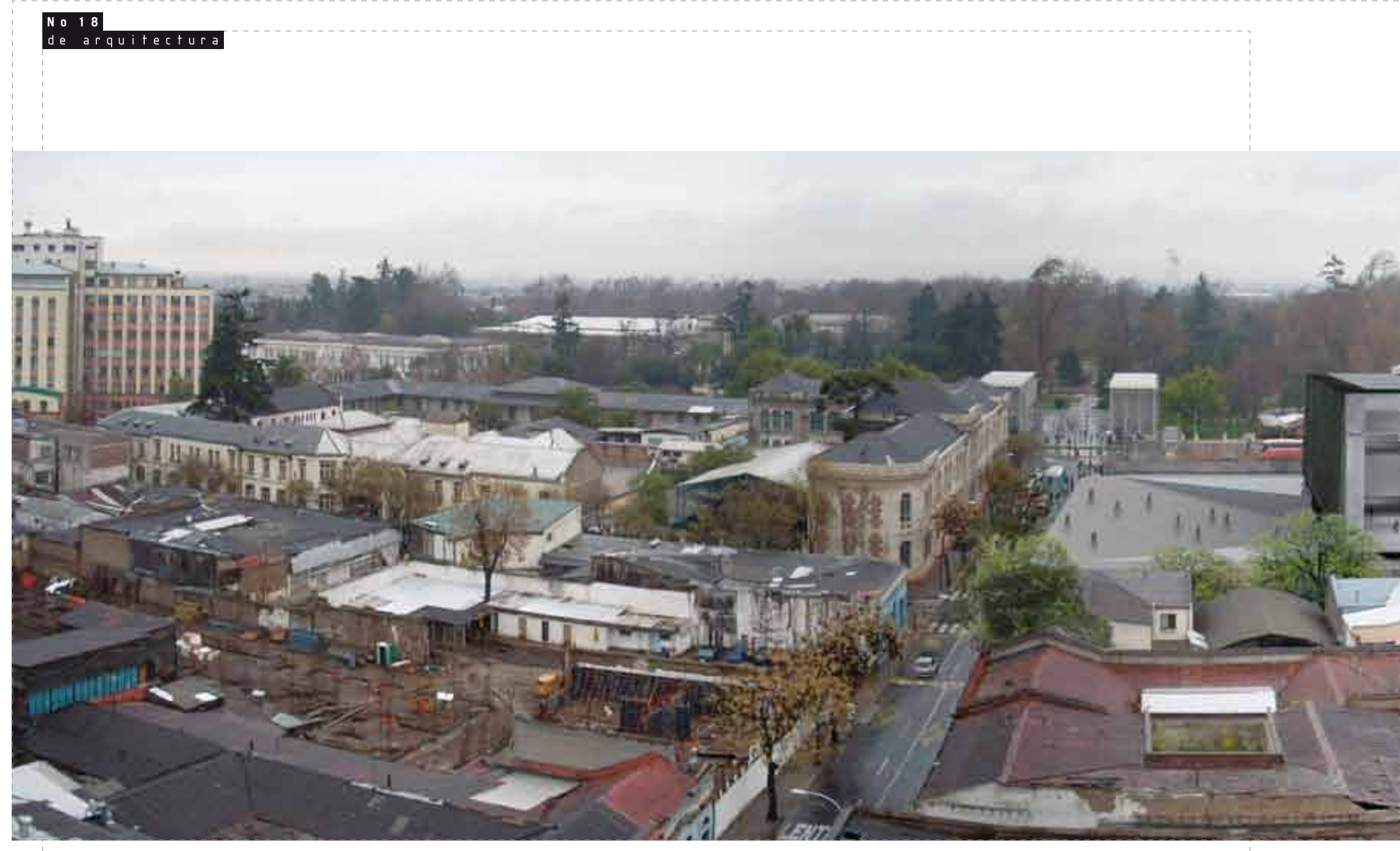

y la Base, como espacio Museológico.

Corredores, en las dos laterales de la Barra,

la circulación, sanitarios y apoyos, iluminados a través de los paneles laterales de vidrio que separan la circulación y la hacen, también,

luz. La manifestación, el florecimiento de este conocimiento es el objetivo contemporáneo de un Museo. Este surge a través de raíces profundas y bien plantadas, en un subsuelo [La Base], donde el potencial, energético, productivo, mineral, la solidez tiene la oportunidad de manifestarse. En su interior, las cajas de vidrio, la transparencia necesaria, la vivacidad; la memoria vivida en fragmentos, pero que forma en conjunto el repertorio de la idiosincrasia de una nación. La masa es el cristal.

\section{Ficha Técnica}

Autor(es): Estudio América. Carlos Dias (Brasil) + Lucas Fehr (Brasil) + Mario Figueroa (Brasil) + Roberto Ibieta (responsable técnico y arquitecto asociado en Chile).

Colaborador(es) Concurso: Amanda Renz + Carlos Eduardo Garcia + Flavia Tenan + Juliana Baldocchi + Juliana Klein + Marcus Vinícius Damon + Marina Canhadas + Ing. Ricardo Dias (estructura) + Josei Nagayassu (video).

Colaborador(es) Ejecutivo(s): Brasil > Amanda Renz + Carlos Eduardo Garcia + Juliana Klein + Marcus Vinícius Damon + Marina Canhadas + Luiz Del Guerra + Gustavo Capecchi; Chile > Werner Renck (arquitecto coordinador) + Luis Madrid (arquitecto) + Ignacio Cárdenas (arquitecto) + Felipe González (arquitecto) + Cristián Pérez (ingeniero) + Álvaro Díaz (dibujante proyectista).
Asesores Técnicos: Ing. Osvaldo Peñaloza (estructuras) + Termosistemas (climatización) + Sipar (sanitario) + Pimesa (electricidad) + Ing. Jaime Hurtado (luminotécnia) + Const. Civil Sergio Dalmazzo (seguridad) + Piscinería (hidráulica) + SolArchi (coodinación general).

Localización: Avenida Matucana, Quinta Normal, Santiago.

\section{Superficie del terreno: $15.727 \mathrm{~m}^{2}$.}

Superficie construida: Concurso > $49.150 \mathrm{~m}^{2}$ (Museo + Centro Matucana + Estacionamiento); Ejecutivo $>10.900 \mathrm{~m}^{2}$ (Museo + Estacionamiento).

Año de proyecto: 2007 (concurso). 2007-2008 (ejecutivo)

\section{Año de construcción: 2008-2009.}

Materiales predominantes: Hormigón armado, acero, cristal y cobre. 


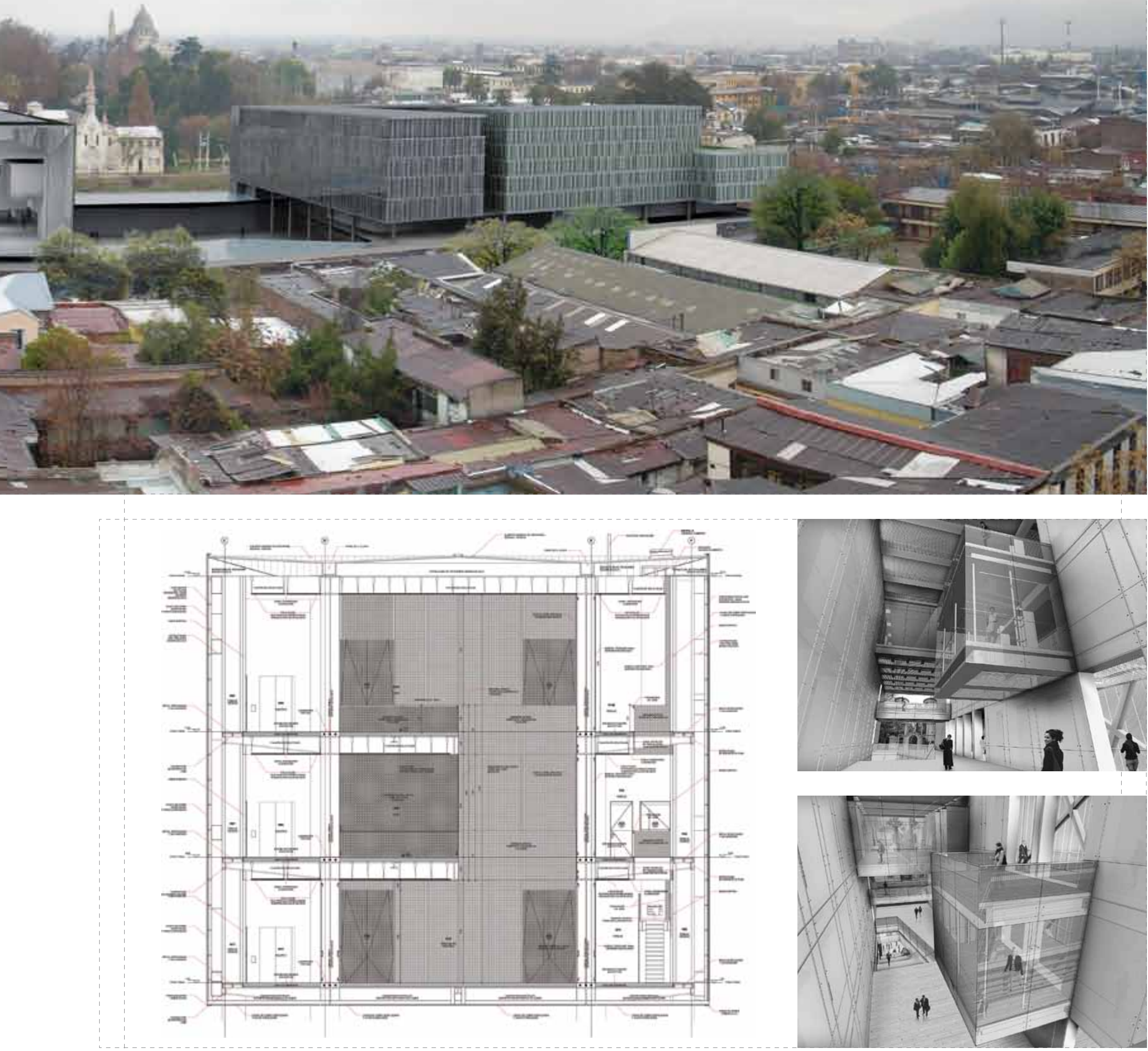


«Experiencia del Visitante»

\section{Segundo Premio: Sebastián Irarrázaval} Arquitectos + Amercanda

- El visitante se lo acoge en Recepción, y se le da un prospecto que contextualiza y orienta su recorrido. Este prospecto contiene una semilla con sus instrucciones de siembra.

- La visita comienza, en Vivir juntos, es un espacio abierto con audio individual, auriculares suspendidos y gráfica en el piso: normas básicas de convivencia, civismo, respeto por los demás, etc.

- Entramos luego a nuestros peores fracasos, período 1973-1990, este espacio muestra en simultáneo 3 niveles de información:

- La calle (Muro derecho en el sentido de la visita): lo cotidiano, lo que se dice y oye entre desconocidos, grafittis, y murales.

- La historia (pantallas en el piso): es una línea de tiempo que contextualiza, es cronológica, (titulares de diarios y análisis histórico). Los ojos, mirando a los ojos: tras el muro, a través de perforaciones en pares se puede ver y leer lo que no debió suceder (pantallas dentro de un muro contienen la información, sólo se puede ver de manera intima a través de las perforaciones, o en los asientos-nichos individuales en el muro para audio e imágenes).

- Espacio de reflexión: frente a la ventana que mira a los transeúntes que circulan por la plaza de acceso al museo: nuestros pares (sólo se ve hacia afuera, los muros están vacíos).

- Nuestras otras historias: Santa María, Seguro Obrero, Puerto Montt... (misma técnica museográfica que el tercer punto).

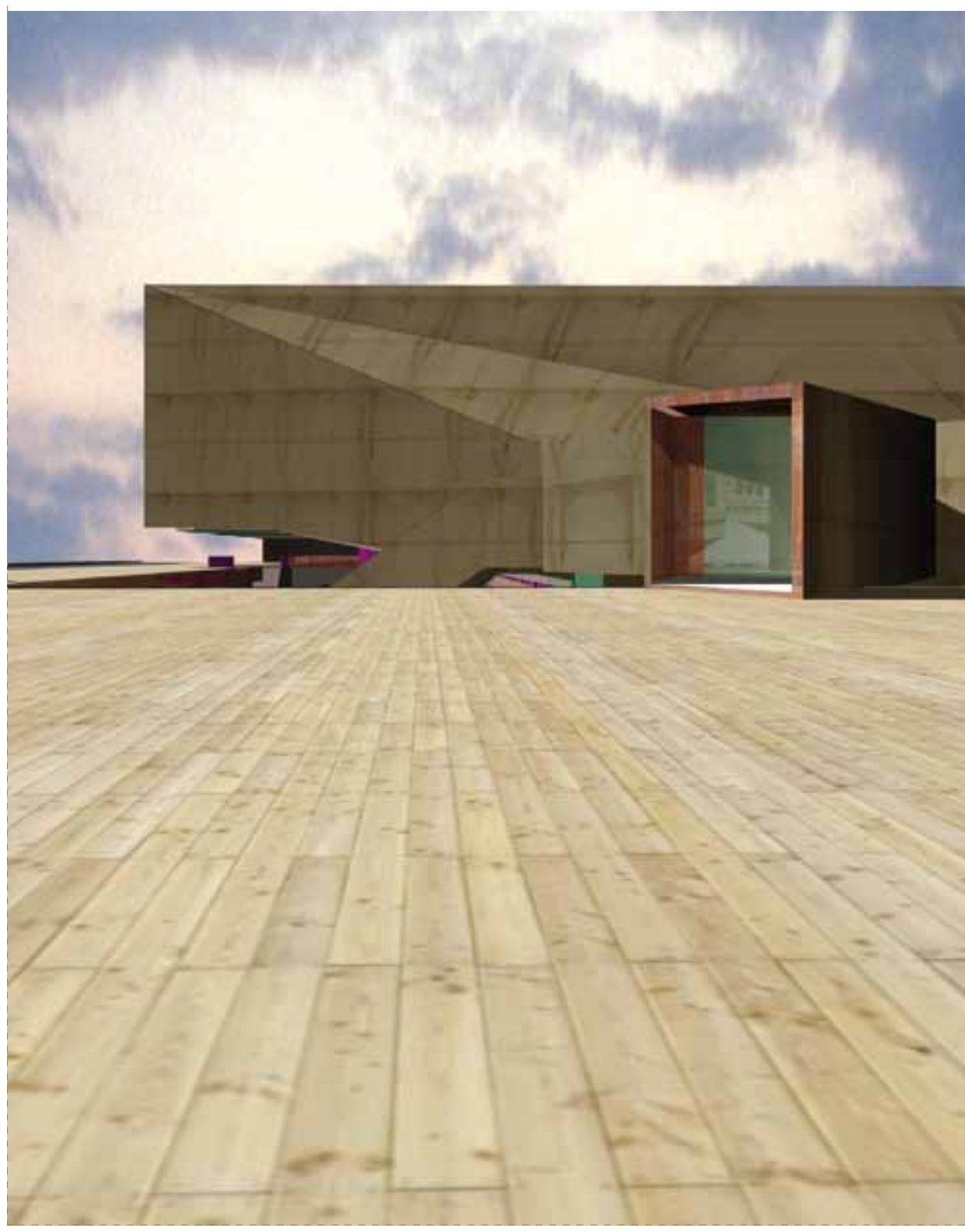

- Rebelión en Chile y el Mundo: imágenes y textos de celebración popular, el día de la liberación, la emoción en la calle que aúna a los ciudadanos.
- Libertad de expresión: al final de la sala de la celebración, terminales de computación permiten escribir en la fachada exterior del edificio, reflexiones, deseos, pareceres que pueden ser leídos por quienes circulan por la plaza.

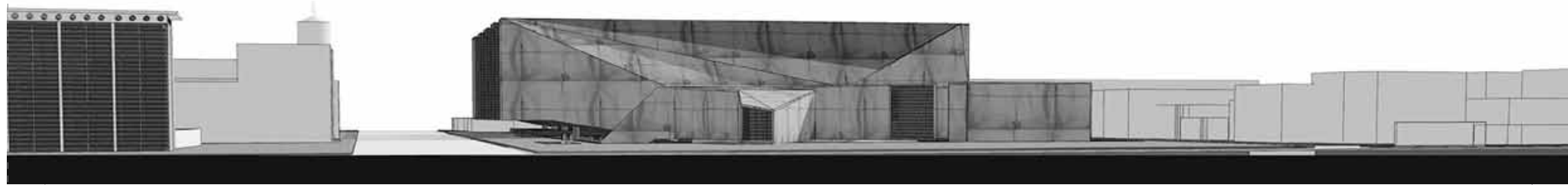



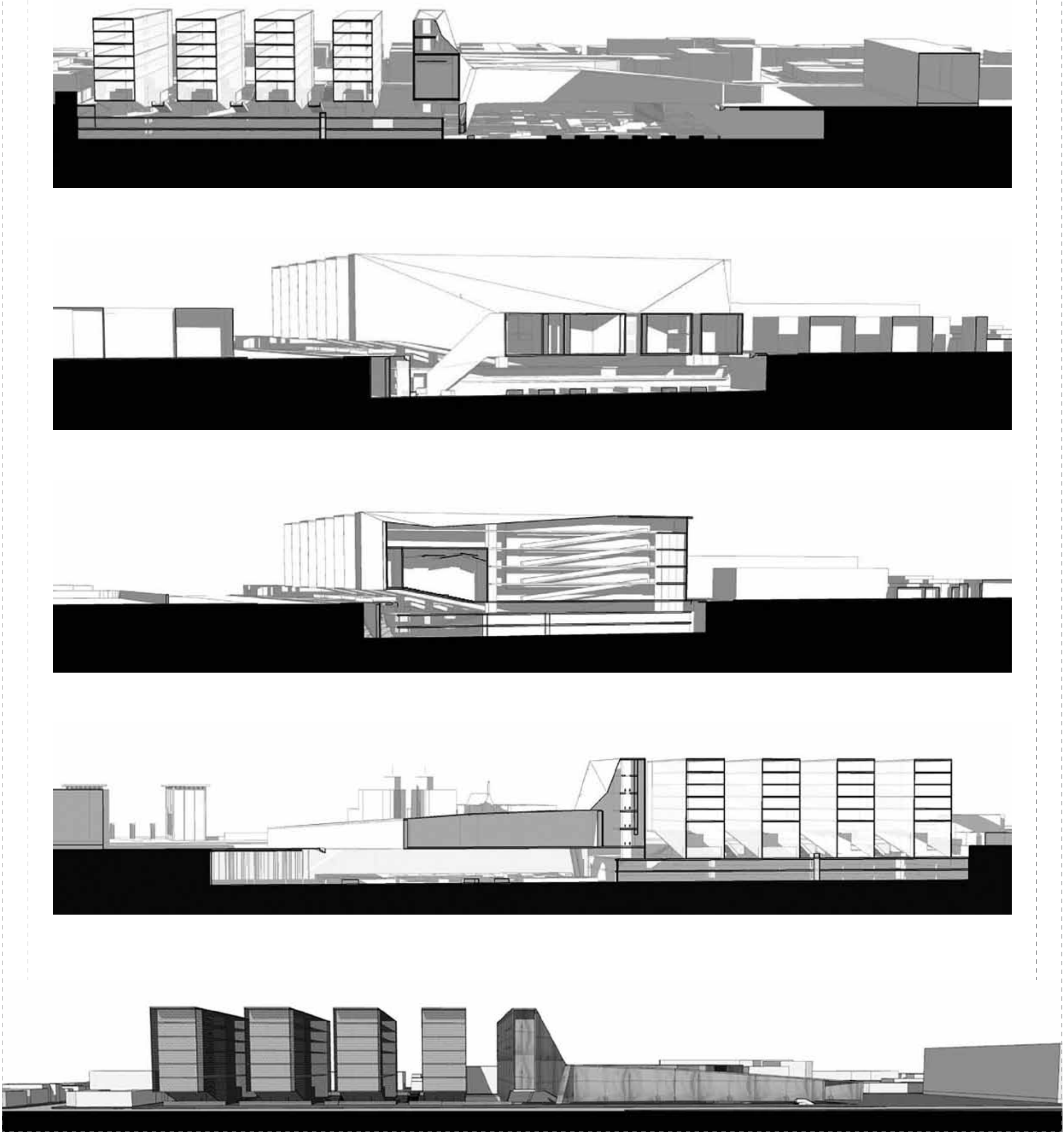

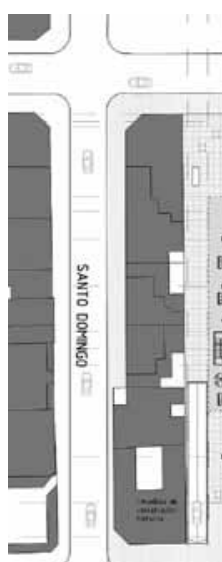

ᄀ

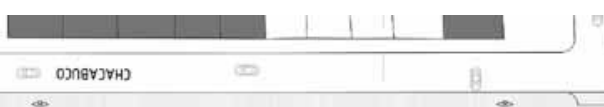

同田

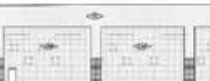

$\mathrm{Bn}^{-1} \mathrm{~m}^{-\infty}$

$\overline{\frac{1}{0}}$

高
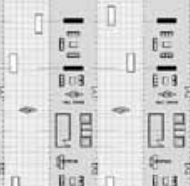

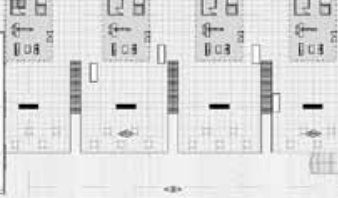
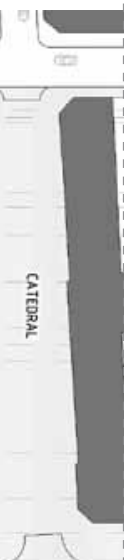

$n$
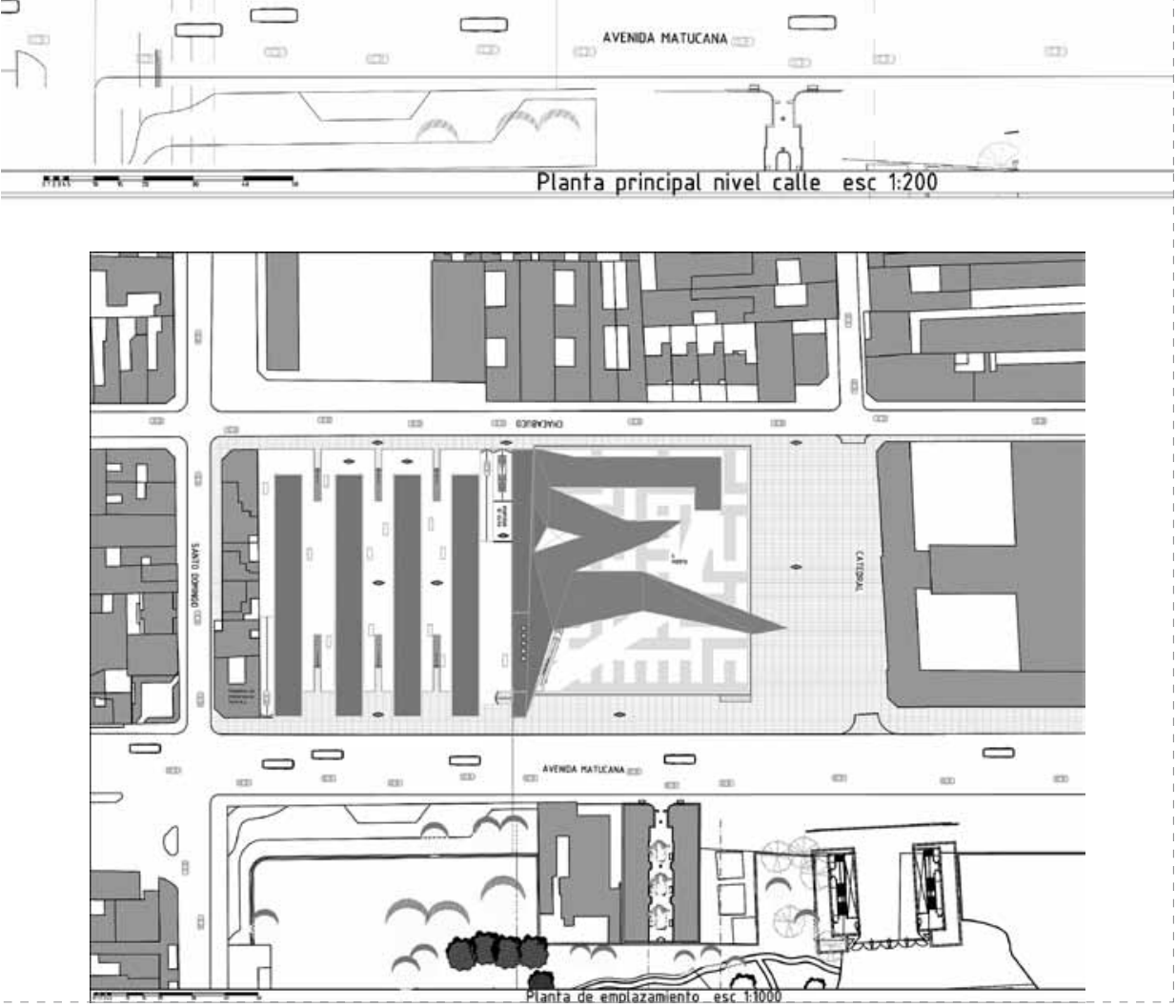

- El Memorial se compone de dos partes: bajando por la gran escalera, El Huerto, un espacio de reflexión, laberinto vegetal en el que se puede plantar la semilla entregada en Recepción, y la Sala de los Nombres bajo la calle Catedral.

- Retorno: Subimos por una escalera mecánica, para ver El Debate (auditorio), la sala de exposiciones temporales frente a la gran Vitrina Archivo, que contiene todos los antecedentes recopilados sobre estos atropellos a los derechos humanos. Esta vitrina se puede recorrer exteriormente en todos sus niveles, y consultar interactivamente los antecedentes. Esta zona, el auditorio y la sala de exposiciones temporales son de recorrido libre.

- Cafetería: En terraza sobre el techo del edificio.

\section{Ficha Técnica}

Autor(es): Chile > Sebastián Irarrázaval + Francisca Rivera + Cristián Irarrázaval + Pablo Cordua + Cristián Valdés.

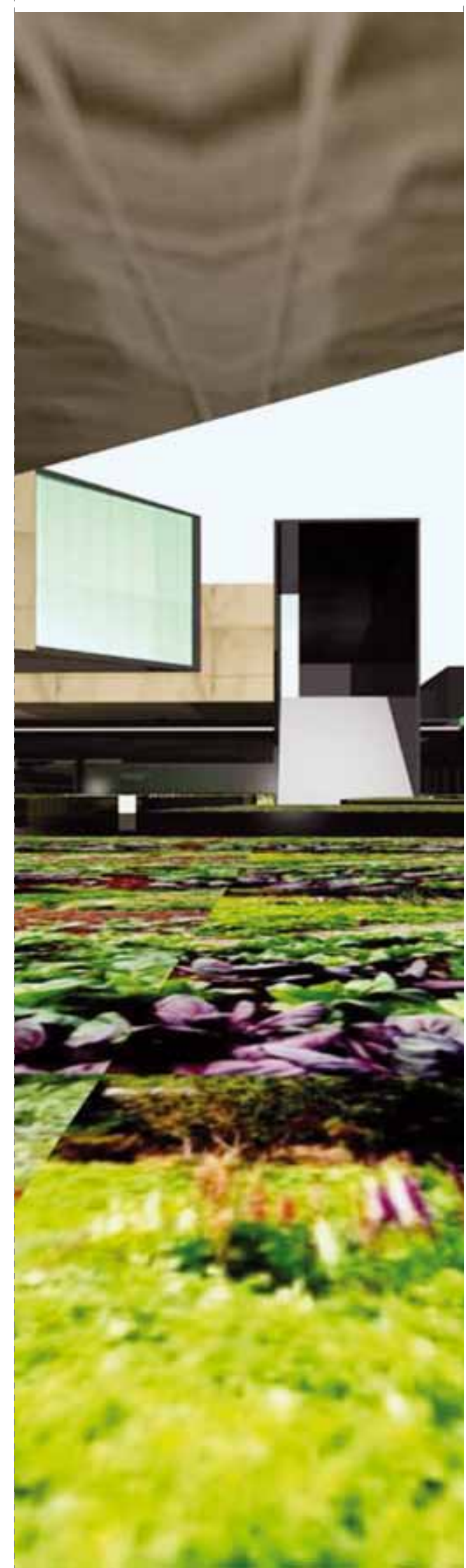


«Reconstrucción

de la Memoria»

\section{Tercer Premio: Mas Fernández Arquitectos}

\section{La Memoria}

- Difícilmente entenderemos nuestra historia y nuestro presente si no experimentamos el proceso de la Memoria.

- La Memoria es una experiencia vital y activa.

- La experiencia de la Memoria nos permite integrar nuestro pasado, situarnos en el presente y proyectar el futuro.

- Para Construir la Memoria necesitamos reunir y procesar distintas vivencias, recuerdos, objetos, testimonios, imágenes y hechos.

- Todos estos elementos antes citados se encuentran dispersos, por lo tanto podemos imaginarnos la reconstrucción de la memoria como un laberinto del cual esperamos salir con un relato articulado, capaz de producir sentido.

- Reunir, conservar y desplegar una memoria de las violaciones a los derechos humanos en Chile, que sea capaz de trascender la mera exhibición para provocar una experiencia y una conciencia en la ciudadanía, es el objetivo central de este proyecto.

\section{La Propuesta}

- En base a lo dicho anteriormente, nuestra propuesta consiste en crear un contenedor, en el que esta experiencia vital de la Memoria pueda no sólo conservarse y ser exhibida, sino también, desarrollarse en un espacio único y múltiple, para así proporcionar una experiencia compleja en el visitante.

- Proponemos como contenedor de la Memoria, un volumen sólido y nítido, que se presenta suspendido sobre el nivel de la calle para de este modo, potenciar el hecho de que la Memoria trasciende en el tiempo y de que al interior del edificio se encuentra reunida.

- Al mismo tiempo, esta necesidad de resaltar el volumen del museo y su capacidad de conservar en el interior una Memoria capaz de gravitar por sobre las contingencias, se potencia por los
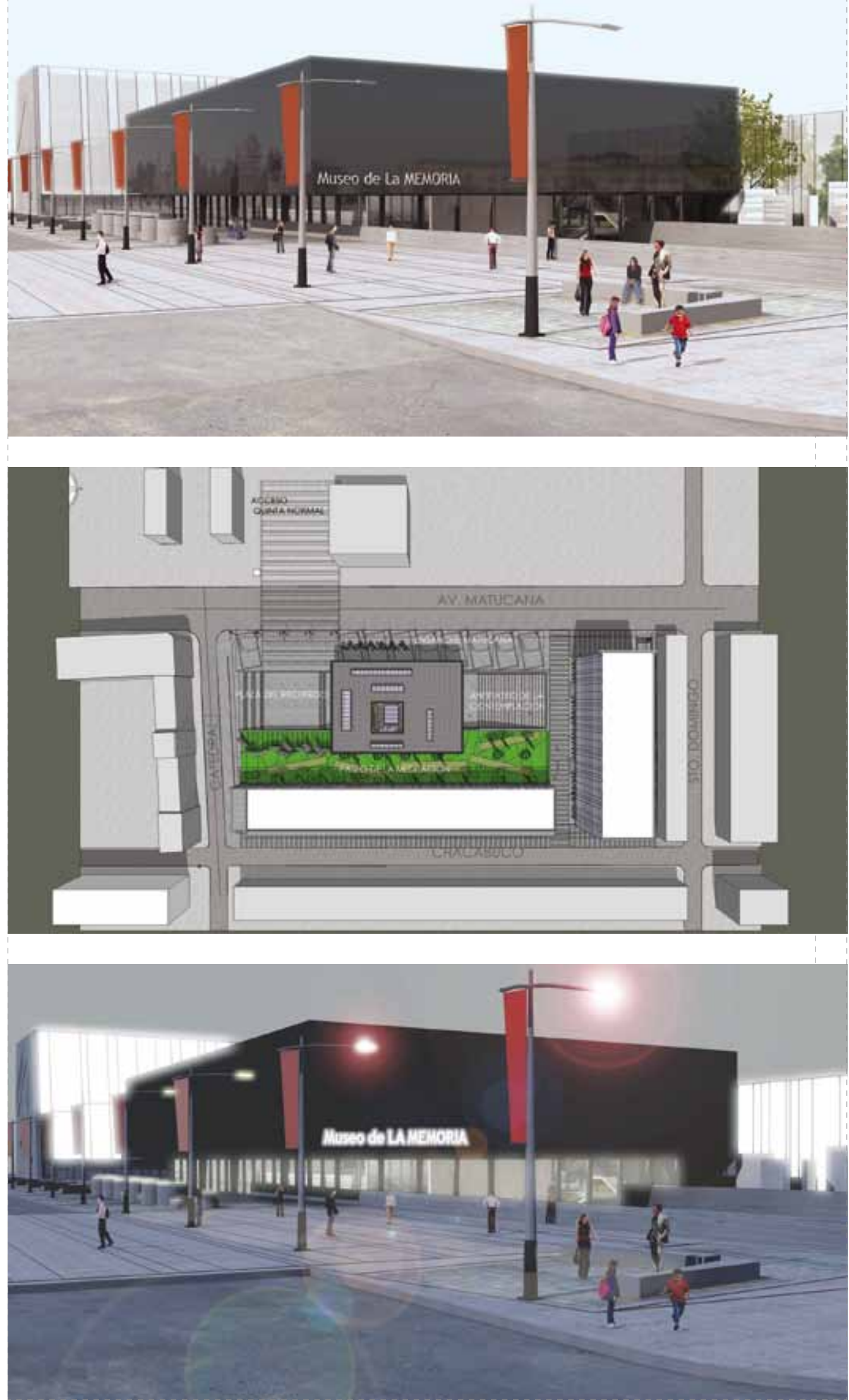
dos edificios que delimitan el perímetro del terreno, los cuales, a través de sus fachadas traslucidas y retroiluminadas realzan la simpleza y pureza del volumen propuesto como también su flotación y horizontalidad, la cual permite relacionar el conjunto con la geografía de Santiago expresada en sus montañas.

- A su vez el volumen del Museo se separa del equipamiento privado y de la calle hacia el oriente, con un parque verde que actúa como diferenciador programático y tiene como finalidad invitar al visitante a la reflexión y lectura de la declaración de los derechos humanos grabada en las diferentes placas verticales ubicadas junto a la salida del Museo. Y hacia el poniente, con un ensanche de la vereda pública, generando una plaza dura que permite aproximarse al borde del edifico, al anfiteatro y a la plaza de acceso

- Para acceder al Museo se propone una plaza en pendiente, que se encuentra comunicada por una parte con un nuevo acceso al Parque de la Quinta Normal, el cual se ubicará en el actual espacio remanente entre la salida del metro y el cité colindante y por otra, a la esquina de las calles Catedral y Av. Matucana.

- En su interior, el Museo busca desarrollar un espacio en donde la reconstrucción de la Memoria de los Derechos Humanos en Chile, sea ascendente y progresiva. Para esto, el Museo se articula a partir de cuatro niveles, todos ellos relacionados por un patio interior que atraviesa el edificio en toda su altura y que en su base contiene el archivo, que para nosotros representa e núcleo simbólico de la Memoria, de esta manera, se busca que desde una Memoria en bruto y traumática, como es la de los testimonios conservados en el subsuelo del edificio, el patio central genere un espacio de conciencia que esté presente a lo largo de todo el recorrido.

- A partir de este vacío central y simbólico, el espacio para la exhibición se desarrolla en los dos niveles interiores del contenedor.
En ellos se pretende desarrollar un recorrido que apelando a la experiencia de la reconstrucción de la Memoria citada en el primer punto, se plantea laberínticamente en torno al patio central, comunicando las diferentes salas a través de pasillos abalconados a éste y a los vacíos que relacionan y dan luz a las diferentes plantas. De este modo, se busca que el visitante vaya progresando en su comprensión y al mismo tiempo, al poder relacionarse visualmente con los diferentes niveles, asimile integralmente lo que ha sido la Memoria de la transgresión a los derechos humanos en la historia de Chile.

\section{Ficha Técnica}

Autor(es): Chile > Mas Fernández Arquitectos / Andrés Mas + Juan Cristóbal Fernández Chadwick + Arquitecto socio Matías Cienfuegos Velasco.

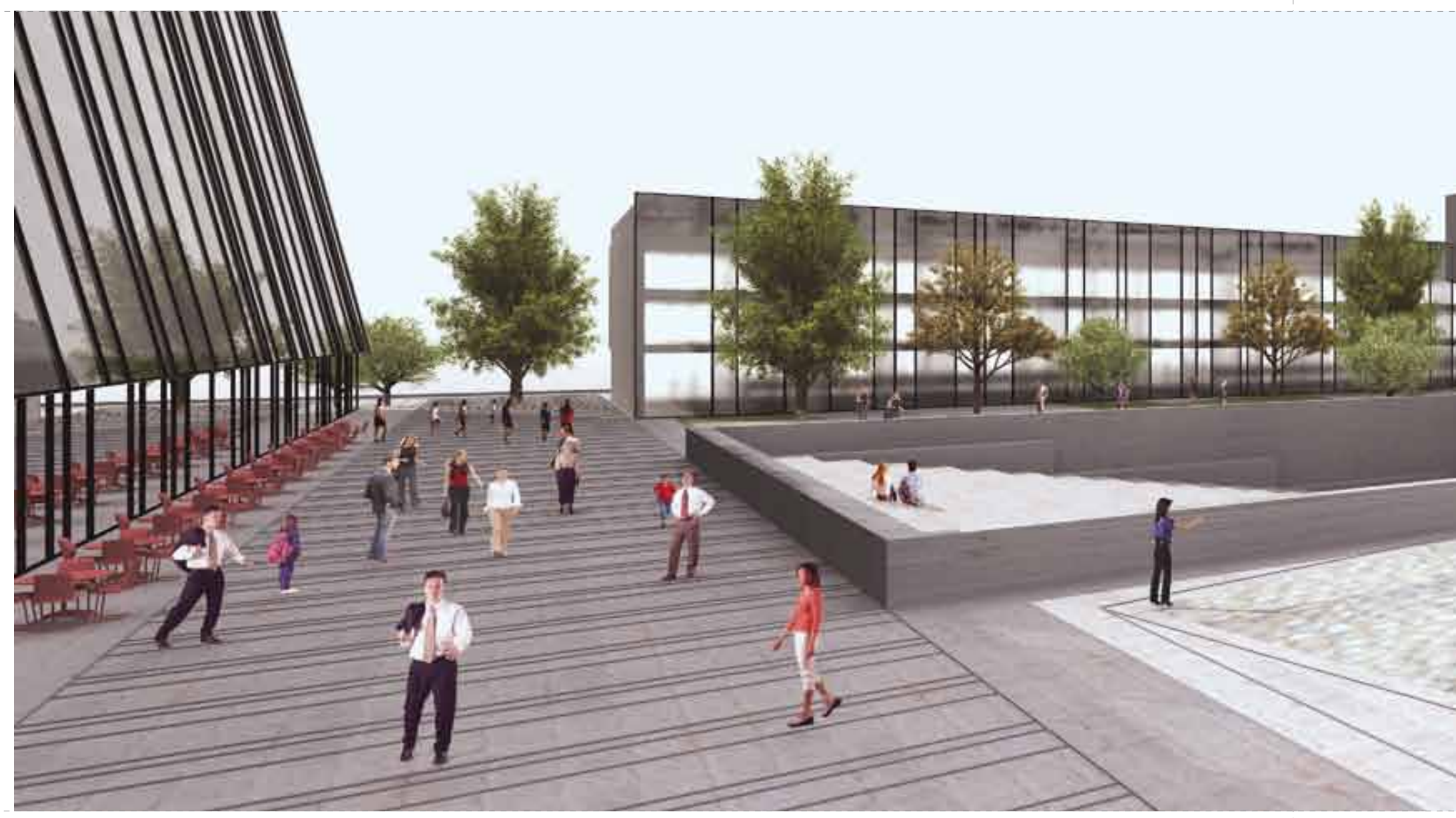



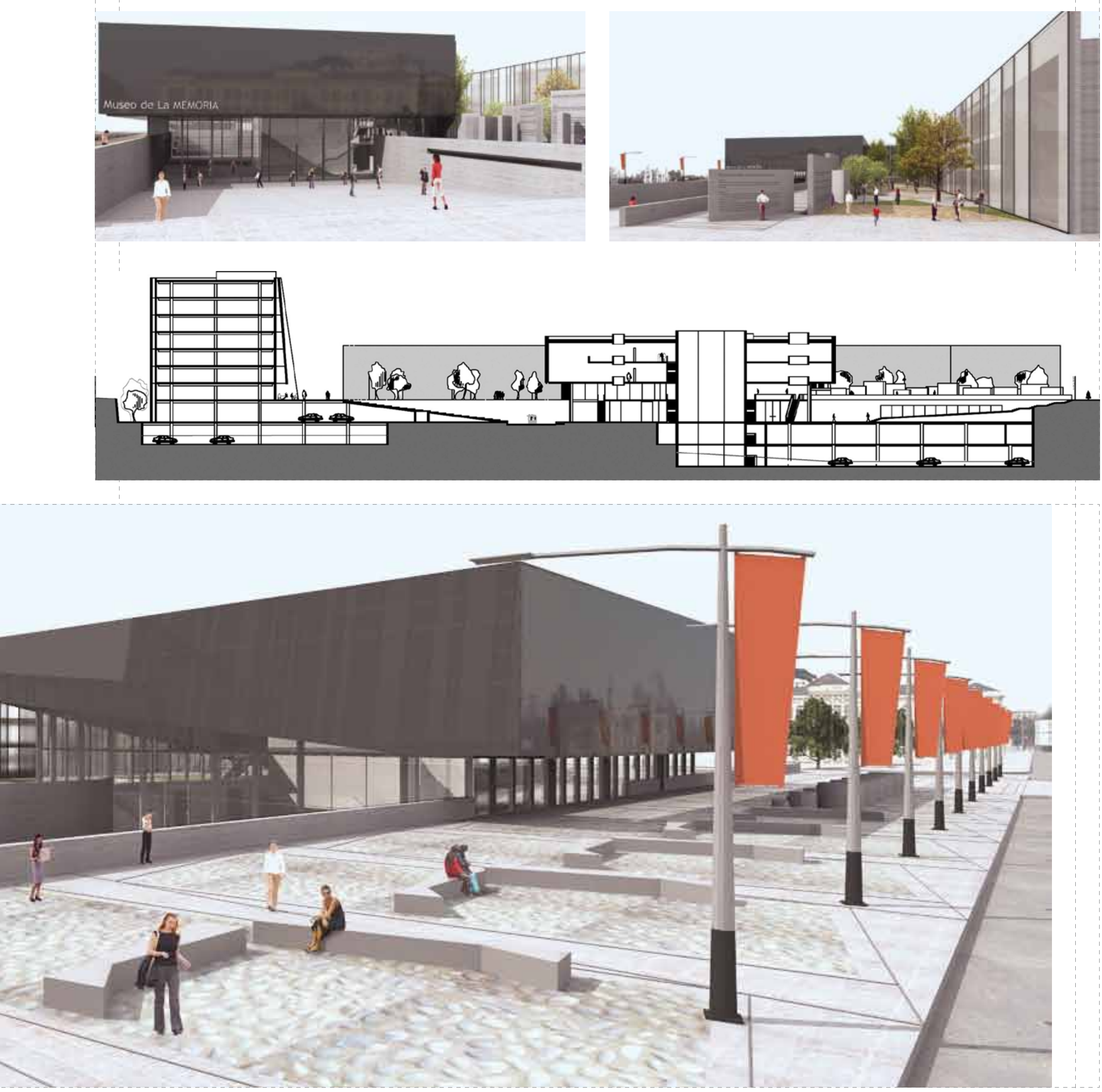